\title{
THE EFFECTS OF \\ INHIBITORS ON THE BIOSYNTHESIS OF THE LONG CHAIN LIPIDS WITH EVEN CARBON NUMBERS IN BARLEY SPIKE EPICUTICULAR WAX
}

by

\author{
JØRN DALGAARD MIKKELSEN
}

Department of Physiology, Carlsberg Laboratory

Gamle Carlsberg Vej 10, DK-2500 Copenhagen, Valby

and

Institute of Genetics, University of Copenhagen

Øster Farimagsgade 2A, DK-1353 Copenhagen K

Keywords: fatty acids, primary alcohols, aldehydes, esters,

${ }^{14} \mathrm{C}$-acetate, cyanide, arsenite, dithiothreitol, mercaptoethanol

The effects of inhibitors on the incorporation of label from $\left[2-{ }^{14} \mathrm{C}\right]$-acetate into the epicuticular wax classes with even carbon numbers have been determined. They include the free fatty acids, the primary alcohols, the aldehydes, the ester acids and a newly identified wax class on barley spikes, the short chain esters. Dithiothreitol, which has no effect on $\beta$-diketone synthesis, inhibits decarboxylation of very long fatty acyl chains which are precursors of the alkanes. Mercaptoethanol, which greatly stimulates wax synthesis at low concentrations and has no effect on $\beta$-diketone synthesis, blocks further elongation of fatty acyl precursors having 20 carbons at higher concentrations. A relatively small inhibition of decarboxylation was also observed with mercaptoethanol. Arsenite, which inhibits $\beta$-diketone synthesis presumably by blocking the entrance of $C_{16}$ precursors into the $\beta$ diketone elongation mechanism, was also found to prevent the $C_{20}-C_{22}$ elongation step in the sequence leading to the alkanes. Cyanide, which blocks $\beta$-diketone synthesis by an unknown mechanism, greatly stimulated synthesis of the other wax classes. At higher concentrations a block in the elongation sequence leading to the alkanes was also apparent between $\mathrm{C}_{26}-\mathrm{C}_{28}$. These results are incorporated into a composite figure illustrating the biosynthetic relationships among the wax classes. All identified chemical and genetic blocks have been included. The conclusion is reached that at least three elongation systems must be involved. 


\section{INTRODUCTION}

Epicuticular wax on barley spikes consists primarily of $\beta$-diketones, hydroxy- $\beta$-diketones, esters, aldehydes, primary alcohols, free fatty acids and on certain genotypes also of secondary alcohols. Barley spikes have already proven to be a suitable system to investigate the biosynthetic relationships among the wax classes $(37,47,51)$. For example, the elongation system leading to the $\beta$-diketones was found to be a different one from that giving rise to the other wax classes (37). The term system is used to include both biochemical and compartmentalization facets of the elongation. The origin of the other wax classes is believed to be as follows: With the aid of an elongation system(s), palmitate or longer fatty acids are elongated by malonyl-CoA to appropriate long chain precursors, which (i) serve as substrates for the decarboxylases leading to alkanes, secondary alcohols and ketones, (ii) serve as substrates for reductases giving rise to aldehydes, free and esterified alkan-l-ols or, (iii) are detached from the elongation system(s) as free fatty acids (23, $26,31,48$ ).

Of great interest at present is the question of whether the elongation to specific chain lengths referred to in the previous sentence involves only one elongation system or more than one. Thus, different elongation systems could conceivably give rise to the fatty acyl precursors of i, ii and iii. Or perhaps, a sequence of elongation systems exists, in which the first elongation is from $\mathrm{C}_{16}-\mathrm{C}_{X}$, the second from $\mathrm{C}_{X^{-}}$ $\mathrm{C}_{Y}$ and the third from $\mathrm{C}_{Y}-\mathrm{C}_{Z}$. In such a situation the various enzymes utilizing the elongated precursors would be restricted to those from only one or perhaps two of the sequential elongation systems. Results from genetic and physiological studies as well as preliminary investigations with thiocarbamates suggest that very likely several elongation systems are functioning. Since the use of inhibitors in conjunction with labelled precursors have proved an effective method to dissect various parts of the wax biosynthetic mechanism(s) $(5,9,10,14-17,19,21,22,29,30$, $36,43)$, this technique might also help resolve the questions of both the number and type of elongation systems involved.

The present communication presents the effects of inhibitors on the incorporation of 12 ${ }^{14} \mathrm{C}$-acetate into wax classes with even chain lengths. These were isolated in the course of the same experiments with $c e r-u^{69}$ in which the biosynthetic relationships of the $\beta$-diketones and alkanes were investigated (37). The observed differential sensivity of some elongation steps to the inhibitors - mercaptoethanol (ME), dithiothreitol (DTT), arsenite and cyanide clearly demonstrates that more than two elongation systems are involved in wax biosynthesis on barley spikes.

\section{MATERIAL AND METHODS}

\subsection{General}

Sources of chemicals, methods of incorporation of $\left[2-{ }^{14} \mathrm{C}\right]$-acetate into whole spikes, techniques of plant culture, location of the radioactive lipids on the thin layer plates (radio-TLC), and determination of the radioactivity in the various lipids by liquid scintillation are described elsewhere (37). The results for the amount of label in the lipid classes separated by thin layer chromatography are the average of at least two independently carried out incorporation experiments. The results for the distribution of radioactivity among the chain lengths of a given wax class are the mean of five injections into the radio gas chromatograph. Identification of the chain lengths within the wax classes was done using internal standards. No significant difference between injections was found using a $x^{2}$-test; in all cases $P$ was greater than $80 \%$.

Abbreviations: DTE $=1$,4-dithioerythritol; DTT = 1,4-dithiothreitol; GLC = gas liquid chromatography; HEA = hexane: diethylether: acetic acid; $\mathrm{ME}=2$-mercaptoethanol; $\mathrm{TCA}=$ sodium trichloroacetate; $\mathrm{TLC}=$ thin layer chromatography; $\mathrm{u}-\mathrm{l}=$ unknown lipid $\mathrm{l} ; \mathrm{u}-2=$ unknown lipid 2. 


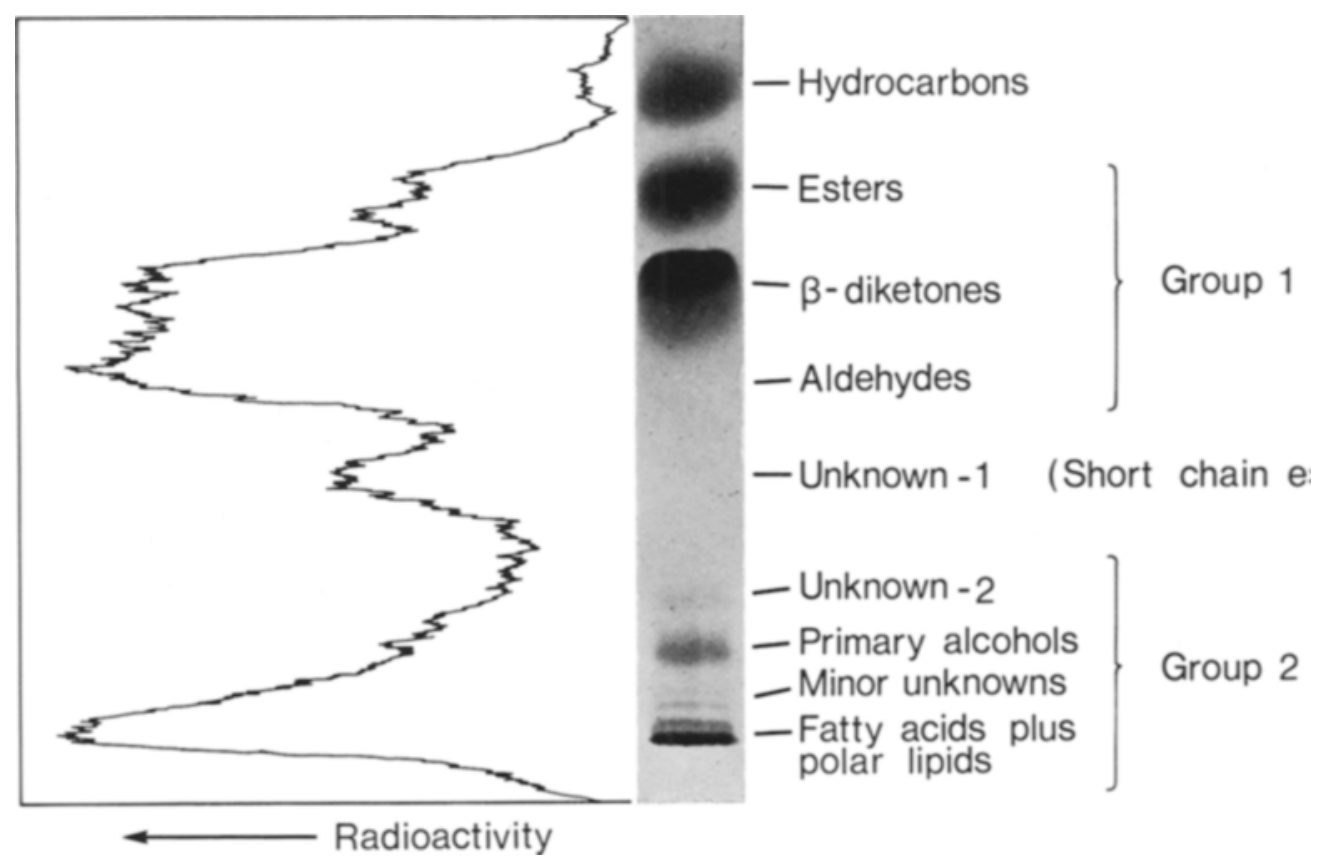

Figure 1. Initial separation by radio-TLC in benzene of surface lipids isolated from whole barley spikes which had been fed $60 \mu$ moles of mercaptoethanol followed by $1.44 \mu$ moles $(83.3 \mu \mathrm{Ci})$ of $\left[2{ }^{14} \mathrm{C}\right]$-acetate. The lipid classes were divided into three groups.

\subsection{Thin layer chromatography (TLC)}

An initial separation of the total epicuticular wax was carried out by preparative TLC using $20 \times 20 \mathrm{~cm}$ plates coated with silica gel $\mathrm{H}$ type 60 (Merck) and benzene as the developing solvent (Fig. 1). The following divisions were made: hydrocarbons; group one lipids consisting of $\beta$-diketones, aldehydes and esters; and group two lipids consisting of free fatty acids, primary alcohols, polar lipids and minor unknowns. Considerable label was also present in an unknown lipid class (u-l) having a retention time in benzene slightly less than the aldehydes after treatment with $60 \mu$ moles ME (Fig. 1). The hydrocarbons, $u-1$ and the lipids of group one were eluted from the silica gel using chloroform. To obtain $100 \%$ recovery of the more polar lipids in group two, hot acidic methanol: chloroform 1:1 (v/v) plus a few drops of " $\mathrm{HCl}$ was used for the extraction. During this procedure the free fatty acids were converted to methylesters (42).

\subsubsection{Separation of lipid classes in group one}

The separation of the three lipid classes in group one using "hybrid" copper acetate TLC plates is described elsewhere (37). Radio-TLC of the aldehydes in benzene and HEA (hexane: diethylether:acetic acid, 70:30:2, v/v/v; 33) showed only one peak (Fig. 2A). Because initial radio-gas liquid chromatography (radio-GLC) of the aldehydes revealed the presence of more than one homologous series, however, the aldehydes from selected treatments were treated as follows. They were reduced to primary alcohols using $\mathrm{NaBH}_{4}$ in $96 \%$ ethanol at $35^{\circ} \mathrm{C}$ for 1 hour, a procedure adapted from Allebone et al. (1) and KolattukUdy (27), and separated from an unreduced fraction by TLC with benzene as shown in Fig. 2B. This unreduced fraction was resistent to repeated exposure to $\mathrm{NaBH}_{4}$ and co-chromatographed with standard aldehydes isolated from sugar cane wax (32) both in benzene and HEA. When aliquots of the unreduced fraction and also $u-1$ 


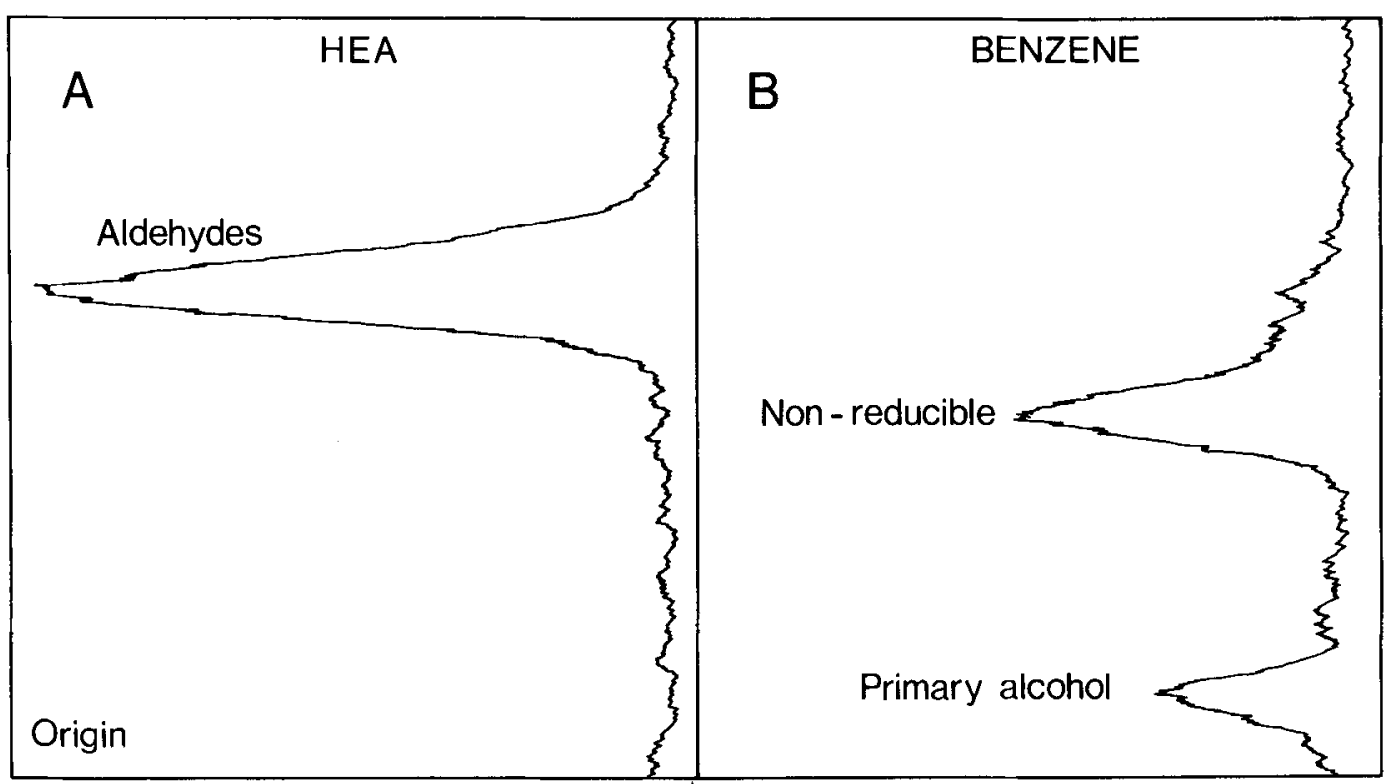

\section{Radioactivity}

Figure 2. Separation of the aldehyde into two lipid classes by reduction with $\mathrm{NaBH}_{4}$. A, before treatment with $\mathrm{NaBH}_{4} ; \mathrm{B}$, after treatment with $\mathrm{NaBH}_{4}$. In both cases silica gel $\mathrm{H}$ plates were used. The true aldehydes were reduced to primary alcohols. The non-reducible fraction has been identified as short chain esters. When estimating the proportion of aldehydes to short chain esters, the radioactivity present in the shoulder of the nonreducible peak was included with that of the main peak. The aldehydes were isolated from wax labeled with [2${ }^{14} \mathrm{Cl}$-acetate after treatment with $6 \mu$ moles arsenite.

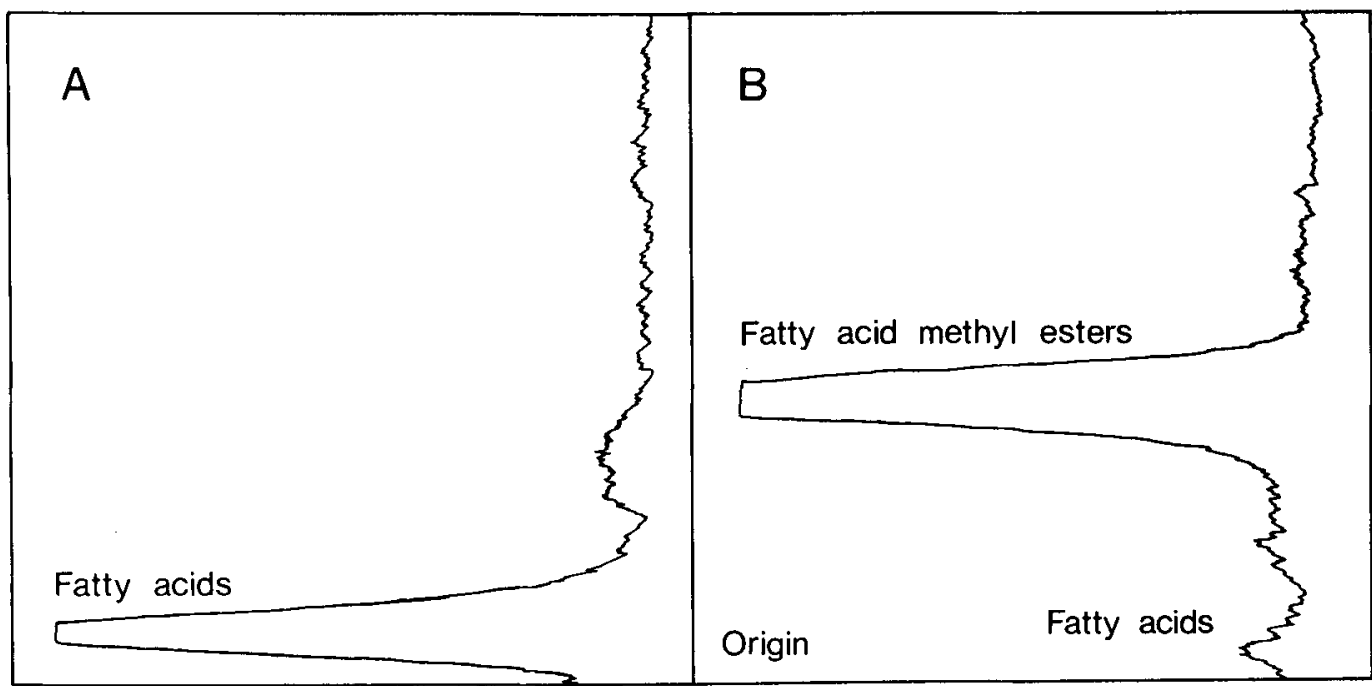

\section{Radioactivity}

Figure 3. Procedure used to demonstrate that the unknown-1 (u-1) of Figure 1 consists of short chain esters. (A) Fatty acids at the origin contain almost all the label subsequent to base hydrolysis of $u-1$. (B) Label is present in methyl esters after $\mathrm{BF}_{3}$ /methanol treatment of the fatty acids. In both cases the separation was carried out on silica gel $\mathrm{H}$ plates using benzene as developing solvent. 
were subjected to base hydrolysis (46) all but a trace of the radioactivity was recovered as free fatty acids (Fig. 3A). U-1 and the unreduced aldehyde fraction when converted to methyl esters and subjected to radio-GLC gave identical traces. These results suggest that the unreduced fraction and $\mathrm{u}-\mathrm{l}$ are in fact esters. The $u-1$ lipid class was apparently resolved in the initial TLC experiments from the group one lipids only in the case of the $60 \mu$ moles ME treatment. This resolution probably depends not only on the relative amounts of label present in these esters and aldehydes, but also on the proportion of the label in the various chain lengths within these two lipid classes. Having established that the non-reducible fraction of the aldehydes were esters, it was more practical in the experiments reported here to carry out a transmethylation reaction to form the methyl esters of the acid moieties for injection into the radio-GLC. The procedure which was adapted from that of BUCKNER and KOLATTUKUDY (5) consisted of a 2 hour treatment of the non-reducible fraction at $80^{\circ} \mathrm{C}$ with $\mathrm{BF}_{3} /$ methanol reagent. Since so little activity was present in the alcohol moieties no attempt was made to identify them. As these esters (i) cochromatograph with the aldehydes which acetate esters are known to do (1), (ii) have a lower $\mathbf{R}_{\mathrm{f}}$ than the well characterized long chain esters and (iii) have fatty acid moieties of similar chain lengths as the long chain esters suggests that the alcohol moieties of the "aldehyde esters" are shorter than those of the long chain esters. Thus, the aldehyde ester fraction will, hereafter, be referred to as short chain esters.

\subsubsection{Separation of lipid classes in group two}

The lipid classes in group two were first subdivided into free fatty acid methyl esters, primary alcohols plus unknown-two (u-2) and polar lipids plus minor unknowns by TLC using HEA as developing solvent (Fig. 4). The primary alcohols plus $u-2$ from selected treatments were extracted using chloroform, applied to. another silica gel $\mathrm{H}$ plate and treated with acetyl chloride (46). This converted the primary alcohols to acetates which allowed them to be

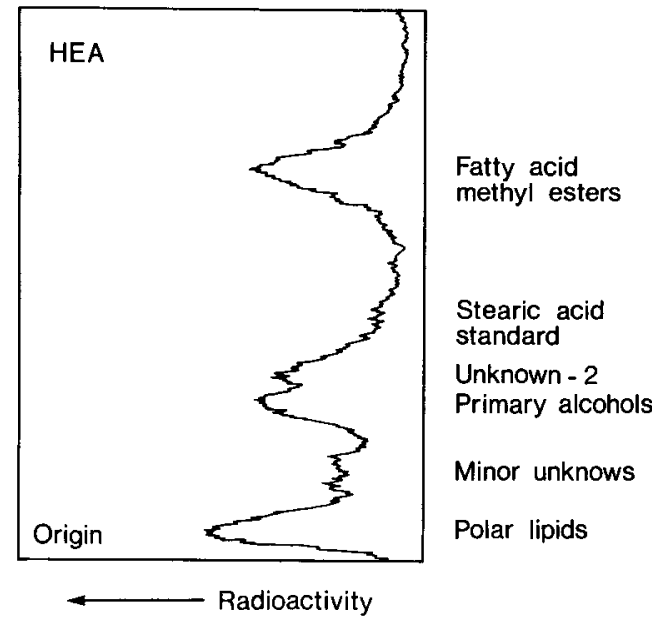

Figure 4. Separation of group two lipids (Fig. 1) by radio-TLC in HEA. The free fatty acids were converted to methyl esters during the extraction of the group two lipids from the silica gel after prelimary separation of wax into groups as shown in Fig. 1.

separated from $\mathrm{u}-2$ by using benzene as the developing solvent $\left(R_{f}\right.$, primary alcohols $=0.06$ 0.09 ; primary alcohol acetates $=0.34-0.39 ; \mathrm{u}-2$ $=0.11-0.14)$.

\subsection{Radio-gas liquid chromatography (radio-GLC)}

Radio-GLC was carried out using a Varian Aerograph 202-1 B series gas chromatograph and a Nuclear Chicago proportional counter (40). Calibration of the instrument, which was carried out as described in (40), allows one to determine the specific activities to two significant figures. All parameters except the temperature program which went from 150 to $250^{\circ} \mathrm{C}$ at a rate of $2^{\circ} \mathrm{C}$ per minute have been detailed elswhere (37).

\section{RESULTS}

\subsection{Incorporation of label into the various epicuticular wax fractions}

Intact barley spikes readily incorporate [2${ }^{14} \mathrm{C}$-acetate into their epicuticular waxes. Separation of the surface lipids by TLC, followed by a quantitative determination of the label present in each lipid class, revealed that 
incorporation was highest in the hydrocarbons $24 \%$, followed by aldehydes plus short chain esters $22 \%$, primary alcohols plus unknown $16 \%$, $\beta$-diketones $14 \%$, polar lipids plus minor unknowns $10 \%$, free fatty acids $9 \%$ and esters $4 \%$. This distribution is quite different from that of the mass (hydrocarbons $15.9 \%$, esters $10.8 \%$, aldehydes $3.7 \%$, $\beta$-diketones $50 \%$, primary alcohols $2.6 \%$, free fatty acids $7 \%$ and some unknowns $9.9 \%$; 50, 51 and P. VON WETTSTEINKNOWLES personal commun.). This indicates that even though an in vivo system has been utilized for the incorporation, the results are not a true facsimile of the actual synthesis of the epicuticular waxes by the plant. The effects of various concentrations of DTT, ME, arsenite, cyanide and TCA on the radioactive distribution of incorporated $\left[2-{ }^{14} \mathrm{C}\right]$-acetate among the esters, aldehydes plus short chain esters, primary alcohols plus $\mathrm{u}-2$, free fatty acids and polar lipids are shown in Tables I to III. In the control experiment $62 \%$ of the label is present in these five wax fractions. With each 10 -fold increase in inhibitor concentration, the proportion of the label present in these five lipid fractions is enhanced to $74-95 \%$ of the total label incorporated into the epicuticular waxes. Simultaneously the label in the hydrocarbons and $\beta$-diketones decreases. Since the effects of the five investigated inhibitors on the synthesis of the latter two wax classes are dealt with in detail elsewhere (37), they will not be further mentioned here.

\subsubsection{Effect of dithiothreitol (DTT)}

Only at the highest concentration of DTT investigated (60 $\mu$ moles) was the total incorporation of label into the wax significantly inhibited (47\%). Examination of the data in Tables I and II reveals that of the five wax fractions of concern the reduction in incorporation of label is most marked in the two components of the aldehyde fraction, that is, true aldehydes and short chain esters. Synthesis of the latter was already affected at $36 \mu$ moles at which concentration aldehyde synthesis was stimulated by $59 \%$. Some inhibition $(48 \%)$ of label incorporation into the primary alcohol plus $u-2$ fraction also occurs at $60 \mu$ moles, but it is not possible from the present data to say whether only one or both types of lipid are affected. At $36 \mu$ moles, however, synthesis of both are increased as was that of the aldehydes (Tables I and III). The stimulatory effect of DTT at this concentration occurred also for the free fatty acids although the total amount of label in the wax remained essentially unchanged.

\subsubsection{Effect of mercaptoethanol (ME)}

Feeding the spikes 0.6 or $6 \mu$ moles of mercaptoethanol resulted in a one-fold increase in the synthesis of all the wax fractions except the free fatty acids which showed only a small increase (28-46\%) in label accumulation (Table I). The initial inhibitory effects of mercaptoethanol on total wax synthesis were found at a concentration of $60 \mu$ moles. The most sensitive wax classes are the primary alcohols followed by $u-2$ showing 60 and $39 \%$ inhibition, respectively (Tables I and III). At the other extreme are the short chain esters whose synthesis is stimulated by $96 \%$ (Tables I and II).

\subsubsection{Effect of arsenite}

In contrast to the results with ME, low concentrations ( 0.6 and $6.0 \mu$ moles) of arsenite have little effect on total wax synthesis or on the individual wax fractions. Interestingly, however, $6 \mu$ moles of arsenite did significantly inhibit accumulation of label in the aldehydes and markedly increased it in the short chain esters (Tables I and II). With $60 \mu$ moles total wax synthesis was reduced to $21 \%$ of the control values. The data in Table $I$ indicate that formation of all wax classes was severely inhibited, the least affected being the aldehyde fraction ( $47 \%$ inhibition). On the basis of the results with $6 \mu$ moles, it is believed that the majority of the label in the aldehyde fraction after treatment with $60 \mu$ moles is in the short chain esters. The latter is a wax class that is synthesized by the spikes on barley plants in only trace amounts relative to the other wax lipids.

\subsubsection{Effect of cyanide}

Low concentrations of cyanide (0.6 and 6 $\mu$ moles) more than doubled the amount of label incorporated into the wax lipids (Table I). As observed with the stimulation by low concentrations of ME, the free fatty acids appear to be 
Table I

Effects of pre-incubations with inhibitors on the incorporation of $\left[2-{ }^{14} \mathrm{C}\right]$-acetate into five fractions of barley spike epicuticular wax which are separable by thin-layer chromatography (TLC) ${ }^{\mathrm{a}}$.

\begin{tabular}{|c|c|c|c|c|c|c|c|c|}
\hline \multirow[b]{2}{*}{$\begin{array}{l}\text { Experimental } \\
\text { condition }\end{array}$} & \multirow[b]{2}{*}{ ( $\mu$ moles) } & \multirow[b]{2}{*}{$\begin{array}{l}\text { Total label } \\
\text { in waxb } \\
\left(\mathrm{cpm} \times 10^{-3}\right)\end{array}$} & \multicolumn{6}{|c|}{$\begin{array}{l}\text { Wax fraction } \\
\left(\operatorname{cpm} \times 10^{-3}\right)\end{array}$} \\
\hline & & & $\begin{array}{l}\text { Polar } \\
\text { lipids } \\
+ \text { minor } \\
\text { unknowns }\end{array}$ & $\begin{array}{l}\text { Fatty } \\
\text { acids }\end{array}$ & $\begin{array}{l}\text { Primary } \\
\text { alcohols } \\
+u-2\end{array}$ & $\begin{array}{l}\text { Aldehydes } \\
\text { + short } \\
\text { chain } \\
\text { esters }\end{array}$ & Esters & $\begin{array}{l}\% \text { of } \\
\text { totalc }\end{array}$ \\
\hline Control & & 1460 & 152 & 134 & $228^{d}$ & $327 \mathrm{e}$ & 61 & 61.8 \\
\hline \multirow[t]{4}{*}{ Dithiothreitol } & $(0.6)$ & 1840 & 283 & 186 & 147 & 350 & 98 & 57.8 \\
\hline & $(6.0)$ & 1640 & 185 & 230 & 248 & 366 & 54 & 66.0 \\
\hline & $(36.0)$ & 1510 & 157 & 233 & $371^{d}$ & $389 \mathrm{e}$ & 113 & 83.6 \\
\hline & $(60.0)$ & 770 & 179 & 122 & 119 & 56 & 146 & 80.8 \\
\hline \multirow[t]{3}{*}{ Mercaptoethanol } & $(0.6)$ & 3020 & 317 & 172 & 556 & 670 & 121 & 60.8 \\
\hline & $(6.0)$ & 2640 & 333 & 196 & 465 & 853 & 145 & 75.5 \\
\hline & $(60.0)$ & 1190 & 113 & 204 & $110^{d}$ & $561 \mathrm{e}, \mathrm{f}$ & 96 & 91.1 \\
\hline \multirow[t]{3}{*}{ Arsenite } & $(0.6)$ & 1210 & 110 & 87 & 241 & 278 & 30 & 61.7 \\
\hline & $(6.0)$ & 1190 & 133 & 124 & $186^{\mathrm{d}}$ & $514^{\mathrm{e}}$ & 45 & 84.2 \\
\hline & $(60.0)$ & 310 & 43 & 38 & 28 & 174 & 12 & 95.2 \\
\hline \multirow[t]{4}{*}{ Cyanide } & $(0.6)$ & 3230 & 433 & 210 & 394 & 611 & 171 & 56.3 \\
\hline & $(6.0)$ & 3360 & 319 & 192 & $450^{d}$ & $867^{e}$ & 188 & 60.0 \\
\hline & $(60.0)$ & 1470 & 182 & 79 & $178 \mathrm{~d}$ & $453 \mathrm{e}$ & 66 & 65.2 \\
\hline & $(360.0)$ & 1050 & 115 & 86 & 191 & 399 & 36 & 78.8 \\
\hline \multirow[t]{3}{*}{ TCA } & $(0.06)$ & 1440 & 124 & 111 & 311 & 262 & 66 & 60.7 \\
\hline & $(0.6)$ & 660 & 103 & 56 & 165 & 90 & 17 & 65.3 \\
\hline & $(6.0)$ & 230 & 68 & 23 & 49 & 24 & 5 & 73.5 \\
\hline
\end{tabular}

a Details of the TLC procedures used are given in the Materials and Methods. By themselves they are insufficient to resolve the various polar lipids plus minor unknowns, the unknown (u-2) from the primary alcohols or the short chain esters from the aldehydes.

b Total amount of label extracted by chloroform which is equivalent to total label in the epicuticular wax.

c Label in the 5 wax fractions/total label in wax (100).

d Relative proportions of primary alcohols and $u-2$ are given in Table III.

e Relative proportions of aldehydes and short chain esters are given in Table 11.

$f$ Also includes $u-1$; that is, a portion of the short chain esters which were partly resolved in the initial TLC in benzene (see Materials and Methods). 
Table II

Percent distribution of label between the aldehydes and the short chain estersa.

\begin{tabular}{lrcc}
\hline $\begin{array}{l}\text { Experimental } \\
\text { condition }\end{array}$ & & & $\begin{array}{l}\text { Short } \\
\text { chain } \\
\text { esters }\end{array}$ \\
\hline Control & & 72 & 28 \\
Dithiothreitol & $(36)$ & 96 & 4 \\
Mercaptoethanol & $(60)$ & 68 & 32 \\
Arsenite & $(6)$ & 31 & 69 \\
Cyanide & $(6)$ & 43 & 57 \\
& $(60)$ & 34 & 66 \\
\hline
\end{tabular}

a These two lipid classes were resolved by reducing the aldehydes to primary alcohols and separating them from the short chain esters by TLC in benzene.

\section{Table III}

Percent distribution of label between the primary alcohols and an unknown (u-2)a.

\begin{tabular}{|c|c|c|c|}
\hline $\begin{array}{l}\text { Experimental } \\
\text { condition }\end{array}$ & ( $\mu$ moles) & $\begin{array}{l}\text { Primary } \\
\text { alcohols }\end{array}$ & $\mathrm{U}-2$ \\
\hline Control & & 61 & 39 \\
\hline Dithiothreitol & (36) & 66 & 34 \\
\hline Mercaptoethanol & $(60)$ & 51 & 49 \\
\hline Arsenite & (6) & 56 & 44 \\
\hline \multirow[t]{2}{*}{ Cyanide } & (6) & 77 & 23 \\
\hline & $(60)$ & 71 & 29 \\
\hline
\end{tabular}

a These two lipid classes were resolved by converting the primary alcohols to acetates and separating them from $u-2$ by TLC in benzene.

the least affected of the wax fractions. Separation of the primary alcohols and $\mathrm{u}-2$ after treatment with $6 \mu$ moles of cyanide (Table III), however, reveals that the stimulating effect is primarily a result of label increase in the primary alcohols. In the aldehyde fraction the short chain esters are preferentially stimulated, amounting to $57 \%$ of the total (Table II). Feeding $60 \mu$ moles of cyanide resulted in incorporation of label to the same extent as in the control. The distribution of label among the wax classes, however, was altered in that synthesis of the short chain esters has been stimulated more than two-fold at the expense of the aldehydes, free fatty acids and $u-2$. With 360 $\mu$ moles of cyanide, total wax synthesis starts to decrease. The aldehyde fraction alone is not inhibited and this is believed to be due to a stimulatory effect on short chain ester synthesis combined with an inhibition of aldehyde synthesis (see analogous results under arsenite).

\subsubsection{Effect of trichloroacetate (TCA)}

Total surface lipid biosynthesis is essentially unaffected in the presence of $0.06 \mu$ moles TCA. The distribution of label, however, is slightly altered with an increased proportion in the primary alcohol plus u- 2 fraction and decreased amounts in the aldehyde fraction and possibly the fatty acids and polar lipids. With increasing concentrations of TCA, a profound inhibition occurs that effects all wax fractions. Thus, unlike the other four investigated inhibitors, TCA does not show marked differences in its action on the synthesis of the individual wax lipids.

\subsection{Distribution of label among the members of individual wax classes}

To examine more closely the mode of action of the different inhibitors of the biosynthesis of the epicuticular wax classes, the distribution of label among the various chain lengths composing given wax classes was determined by radioGLC. The analyses were carried out on the lipid classes isolated from selected inhibitor treatments. Selection of the given inhibitor concentrations examined was based on their effect on total wax synthesis as well as on the $\beta$ diketones and/or hydrocarbons (37).

\subsubsection{Aldehydes}

The aldehydes, which had been reduced to primary alcohols, were analysed by radio-GLC as their acetates. The observed mass distribution is very similar to the radioactivity distribution of the aldehydes obtained in the control experiment (Table IV). In the presence of DTT, the radioactive distribution of the aldehydes was unchanged although synthesis of all chain lengths was increased. Treatment with the other three inhibitors, however, resulted in rather striking changes in the distribution of label among the aldehydes. Firstly, label in the shorter chain lengths $\mathrm{C}_{16}-\mathrm{C}_{24}$ increased from $2 \%$ 
in the control to $15-38 \%$ after ME, cyanide and arsenite treatments. Whereas in the control the label was present only in the $C_{20}$ chain length, in the inhibitor treatments the $\mathrm{C}_{18}, \mathrm{C}_{22}$ and $\mathrm{C}_{24}$ aldehydes were also labelled. Most interestingly the $\mathrm{C}_{16}$ chain length also accumulated label but only after treatment with ME. Secondly, a marked inhibition $(\cong 58 \%)$ of the synthesis of the $\mathrm{C}_{30}$ and $\mathrm{C}_{32}$ chain lengths occurred after treatment with $60 \mu$ moles of cyanide and 6 $\mu$ moles of arsenite. Treatment with ME, however, had little effect on the synthesis of these long aldehydes.

\subsubsection{Free fatty acids}

The radioactivity distribution of the free fatty acids is surprisingly similar to that of the mass (Table V), and in both cases there is a suggestion of a two headed curve. Treatment with the inbibitors resulted in several marked changes in the pattern of incorporation of ${ }^{14} \mathrm{C}$. In the presence of DTT and ME, the synthesis of the long chain fatty acids $\mathrm{C}_{28}-\mathrm{C}_{32}$ was inhibited while a four-fold increase of label occurred in the short chain fatty acids $\mathrm{C}_{16}-\mathrm{C}_{20}$. The shortest of these is the $\mathrm{C}_{16}$ acid in which no label was found in the control or after the cyanide or arsenite treatments. Both of the latter inhibitors, however, stimulated incorporation of label into $\mathrm{C}_{18}$ and $\mathrm{C}_{20}$ acids. After feeding the spikes $6 \mu$ moles of cyanide or arsenite, label accumulated to the same extent in the $\mathrm{C}_{32}$ acid as it did in the control experiment although synthesis of the other long acids was somewhat reduced. Increasing the cyanide concentration to $60 \mu$ moles also resulted in the inhibition of the synthesis of the $\mathrm{C}_{32}$ acid. The amount of label present in the fatty acids of medium chain length $\left(\mathrm{C}_{22}-\mathrm{C}_{26}\right)$ was also affected by the inhibtior treatments, but no consistent pattern of change is visible except in the arsenite treatment which reduced the amount of label in all three.

\subsubsection{Primary alcohols}

The radioactivity and mass distributions (49) of the primary alcohols are quite different (Table VI). The $\mathrm{C}_{32}$ alcohol which has $40 \%$ of the label represents only $3 \%$ of the mass while the $\mathrm{C}_{26}$ alcohol has only $25 \%$ of the label, but forms $58 \%$ of the mass. Feeding the inhibitors brought about some interesting changes in the incorporation pattern. DTT slightly inhibited synthesis of the $\mathrm{C}_{26}$ chain, and stimulated syn-

\section{Table IV}

Effects of pre-incubations with inhibitors on the incorporation of $\left[2-{ }^{14} \mathrm{C}\right]$-acetate into the aldehydes of barley spike epicuticular waxa.

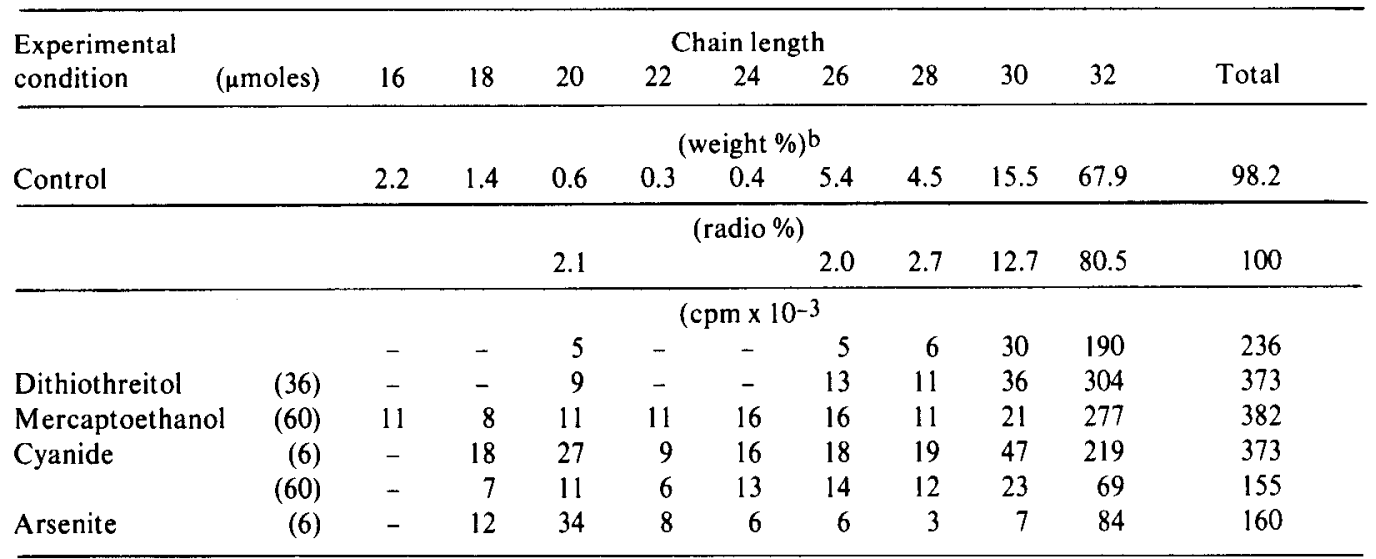

a Analysed as alcohol acetates.

b Since the other peaks present in the mass trace amounting to approximately $1.8 \%$ of the total aldehydes were not radioactive, they are not listed separately here.

$-=$ Not detected. 
Tabel V

Effects of pre-incubations with inhibitors on the incorporation of $\left[2-{ }^{14} \mathrm{C}\right]$ - acetate into the free fatty acids of barley spike epicuticular waxa.

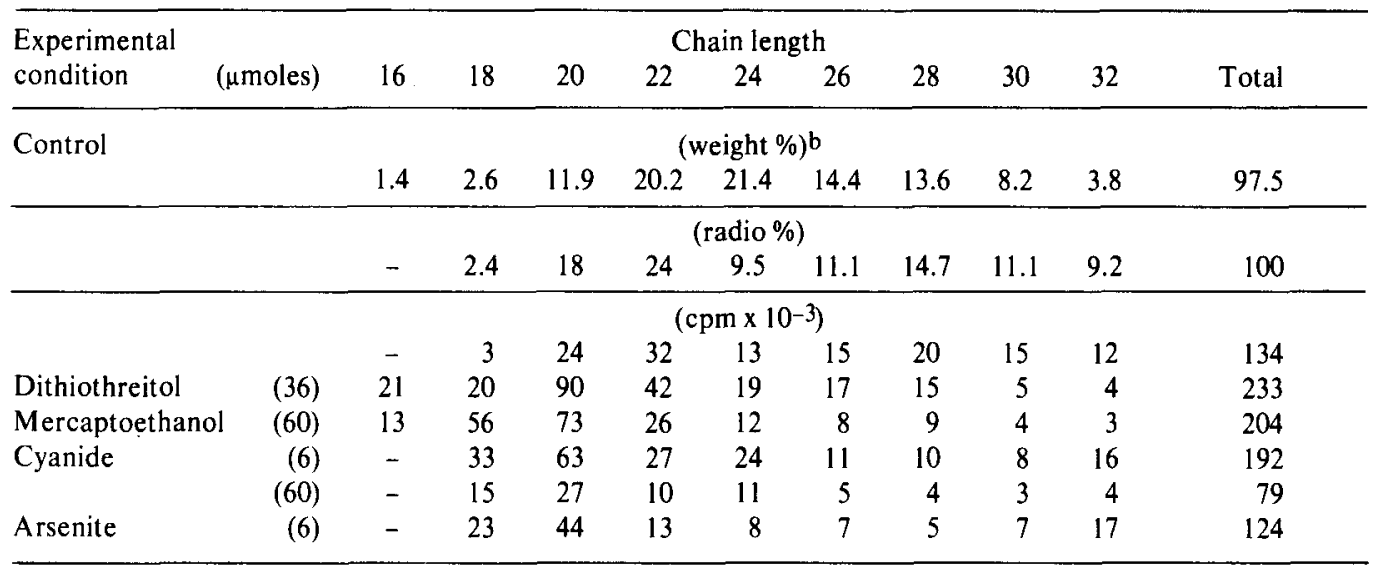

a Analysed as methyl esters.

b Data from (49). Since the other peaks present in the mass trace amounting to approximately $2.5 \%$ of the total free acids were not radioactive, they are not listed separately here.

$-=$ Not detected

\section{Table VI}

Effects of pre-incubations with inhibitors on the incorporation of $[2-14 \mathrm{C}]$-acetate into the primary alcohols of barley spike epicuticular waxa.

\begin{tabular}{|c|c|c|c|c|c|c|c|c|c|}
\hline \multirow{2}{*}{$\begin{array}{l}\text { Experimental } \\
\text { conditions }\end{array}$} & \multicolumn{9}{|c|}{ Chain length } \\
\hline & ( $\mu$ moles) & 20 & 22 & 24 & 26 & 28 & 30 & 32 & Total \\
\hline \multirow[t]{6}{*}{ Control } & \multicolumn{9}{|c|}{ (weight \%) ${ }^{\mathrm{b}}$} \\
\hline & & 2.2 & 2.6 & 9.7 & 57.5 & 14.7 & 5.5 & 3 & 95.2 \\
\hline & \multicolumn{9}{|c|}{ (radio \%) } \\
\hline & & & & 3.9 & 25.1 & 12.6 & 18.0 & 40.4 & 100 \\
\hline & \multicolumn{9}{|c|}{$\left(\mathrm{cpm} \times 10^{-3}\right)$} \\
\hline & & - & - & 5 & 35 & 18 & 25 & 56 & 139 \\
\hline Dithiothreitol & $(36)$ & - & - & 9 & 22 & 17 & 48 & 149 & 245 \\
\hline Mercaptoethanol & $(60)$ & 3 & - & 4 & 11 & 6 & 6 & 26 & 56 \\
\hline \multirow[t]{2}{*}{ Cyanide } & (6) & - & - & 8 & 119 & 63 & 43 & 113 & 346 \\
\hline & $(60)$ & - & - & 4 & 59 & 24 & 15 & 24 & 126 \\
\hline Arsenite & (6) & 3 & - & 4 & 27 & 11 & 8 & 51 & 104 \\
\hline
\end{tabular}

a Analysed as alcohol acetates.

b Data from (49). Since the other peaks present in the mass trace amounting to approximately $4.8 \%$ of the total primary alcohols were not radioactive, they are not listed separately here.

$-=$ Not detected. 
thesis of the $\mathrm{C}_{30}$ and $\mathrm{C}_{32}$ alcohols by 92 and $166 \%$, respectively. ME blocked incorporation of label into all the different chain lengths, but did not significantly alter the distribution of label. By contrast $6 \mu$ moles of cyanide stimulated synthesis of them all. When the cyanide concentration was increased to 60 $\mu$ moles, only $\mathrm{C}_{26}$ formation was still elevated (71\%), while that of the $\mathrm{C}_{30}$ and $\mathrm{C}_{32}$ alcohols was reduced $(51 \%)$. This is the opposite effect of treatment with DTT. At the concentration of arsenite investigated, no marked changes were found in the distribution of radioactivity among the different alcohols.

\subsubsection{Short chain ester fatty acids}

Among the acid moieties of the short chain esters, the $\mathrm{C}_{20}$ acid is by far the most heavily labelled $(48 \%)$ while the $\mathrm{C}_{32}$ acid has $16 \%$ of the label (Table VII). After the inhibitor treatments label was never found in the $\mathrm{C}_{32}$ or $\mathrm{C}_{30}$ acids, but accumulated instead in the shorter homologues. In all but the $\mathrm{ME}$ experiment in which the $C_{16}$ acid was labelled, $C_{18}$ was the shortest chain length with ${ }^{14} \mathrm{C}$. The largest accumulation of label in the $\mathrm{C}_{18}-\mathrm{C}_{26}$ acids (a sixfold increase) occurred after treatment with 6 $\mu$ moles of cyanide. Increasing the amount of cyanide to $60 \mu$ moles, resulted in a significant decrease of label to four times the amount in the control experiment. This decrease was selective, in that only the $C_{18}-C_{22}$ acids were affected.

No mass trace was obtained during the radioGLC of these fatty acid methyl esters. At the sensitivity at which the apparatus was being used (40), as little as 3.7 nmoles of palmitic acid methyl ester could have been seen. The obtaining of mass traces under these conditions for all other wax classes investigated, implies that these fatty acid moieties have the highest specific activity of all the wax lipids investigated to date.

\subsubsection{Esters}

The radioactive distribution of the ester acids is similar to that of the mass in that $\mathrm{C}_{20}$ is the dominant chain length in both (Table VIII). The two distributions differ, however, in that no label is present in the $\mathrm{C}_{16}$ chain which accounts for $12 \%$ of the mass. Treatment with $\mathrm{ME}$ and DTT did not change the radioactive distribution drastically, although the $C_{16}$ and $C_{18}$ chains became more prominent. The similarity between the distribution of label in the acids of the short chain esters (Table VII) and the esters (Table VIII) is very clear after treatment with ME.

\section{Table VII}

The effects of pre-incubations with inhibitors on the incorporation of $\left[2-{ }^{14} \mathrm{C}\right]$-acetate into the fatty acid moieties from the short chain esters of barley spike epicuticular wax ${ }^{a}$.

\begin{tabular}{|c|c|c|c|c|c|c|c|c|c|c|c|}
\hline \multirow{2}{*}{$\begin{array}{l}\text { Experimental } \\
\text { condition }\end{array}$} & \multicolumn{11}{|c|}{ Chain length } \\
\hline & ( $\mu$ moles) & 16 & 18 & 20 & 22 & 24 & 26 & 28 & 30 & 32 & Total \\
\hline \multirow[t]{4}{*}{ Controlb } & \multicolumn{11}{|c|}{ (radio $\%)$} \\
\hline & & & 6.7 & 47.8 & 10.1 & 8.2 & 5.5 & 1.9 & 4.3 & 15.5 & 100 \\
\hline & \multicolumn{11}{|c|}{$\left(\mathrm{cpm} \times 10^{-3}\right)$} \\
\hline & & & 6 & 44 & 9 & 8 & 5 & 1 & 4 & 14 & 91 \\
\hline Mercaptoethanol & $(60)$ & 12 & 49 & 79 & 24 & 10 & 3 & 3 & - & - & 180 \\
\hline \multirow[t]{2}{*}{ Cyanide } & $(6)$ & - & 132 & 176 & 68 & 83 & 34 & - & - & - & 493 \\
\hline & $(60)$ & - & 50 & 83 & 43 & 83 & 39 & - & - & - & 298 \\
\hline Arsenite & (6) & - & 77 & 199 & 45 & 34 & - & - & - & - & 355 \\
\hline
\end{tabular}

a Since the short chain esters contained only $16 \times 10^{-3} \mathrm{cpm}$ in the presence of $36 \mu$ moles of dithiothreitol, their fatty'acid moieties were not subjected to radio-GLC. Analysed as methyl esters.

b Mass peaks were not present in the radio-GLC traces, see text.

$-=$ Not detected. 
Table VIII

The effects of pre-incubations with inhibitors on the incorporation of $\left[2-{ }^{14} \mathrm{C}\right]$ - acetate into the esters of barley spike epicuticular wax.a

\begin{tabular}{|c|c|c|c|c|c|c|c|c|}
\hline \multirow{2}{*}{$\begin{array}{l}\text { Experimental } \\
\text { condition }\end{array}$} & \multicolumn{7}{|c|}{$\begin{array}{l}\text { Ester acidsb } \\
\text { Chain length }\end{array}$} & \multirow{2}{*}{$\begin{array}{c}\text { Ester alcohols } \\
\text { Total }\end{array}$} \\
\hline & ( $\mu$ moles) & 16 & 18 & 20 & 22 & 24 & Total & \\
\hline & & \multicolumn{5}{|c|}{ (weight $\%)^{c}$} & & \\
\hline & & 12.4 & 13.4 & 50.8 & 19.4 & 2.0 & 98 & \\
\hline \multirow[t]{4}{*}{ Control } & & \multicolumn{5}{|c|}{ (radio \%) } & & \\
\hline & & - & 6.8 & 69.5 & 20.4 & 3.3 & 100 & \\
\hline & & \multicolumn{5}{|c|}{$\left(\mathrm{cpm} \times 10^{-3}\right)$} & & \\
\hline & & - & 3 & 33 & 10 & 2 & 48 & 13 \\
\hline Dithiothreitol & $(36)$ & 3 & 10 & 41 & 16 & 3 & 73 & 40 \\
\hline Mercaptoethanol & $(60)$ & 3 & 21 & 36 & 14 & 2 & 76 & 20 \\
\hline
\end{tabular}

a The esters were transesterified and the resulting fatty acid methyl esters and alcohols were separated on silica gel $\mathrm{H}$ plates using benzene. Estimation of the label present was carried out as described in (37). results based on a single determination.

b Analysed as methyl esters. Results based on single injections into the radio-GLC.

c Data taken from (49).

$-=$ Not detected

\section{DISCUSSION}

When an enzyme in a metabolic pathway is blocked by a chemical inhibitor or mutant gene, it would be predicted that the concentration of its substrate tends to increase. Although numerous examples of such substrate increase have been reported, inhibition of an enzyme in a metabolic sequence is not invariably followed by an accumulation of the substrate for this enzyme. Earlier intermediates may also accumulate, sometimes in larger amounts than the immediate precursor. In addition, alternate pathways for the metabolism of any of the preceding intermediates may exist so that the block will result in a shift of the precursors into another pathway. Thus in trying to determine where a gene or inhibitor exerts its effects in a biosynthetic pathway, an examination of all the preceding intermediates as well as of compounds in possible branching pathways should be made. This type of analysis may reveal not only the point at which the block occurs but may often lead to an increased knowledge of the biosynthetic relationships of a given group of compounds.
The present study was concerned with the biosynthesis of the long chain epicuticular lipids, in which the various lipid classes consist of a number of chain lengths with either the odd or even chains predominating. Fig. 5 which presents the biosynthetic relationships of the wax classes is a summary of the information available in the literature and the present results $(2,5,9,10,12-17,19,21,22,29-31,34-38$, $43,47,48,51)$. At least two independent elongation systems exist, one leading to the $\beta$ diketones, hydroxy- $\beta$-diketones and esterified alkan-2-ols and the other giving rise to the hydrocarbons, secondary alcohols, ketones and perhaps also to the aldehydes, primary alcohols and free fatty acids. In looking for the site(s) of action of the investigated inhibitors, ME, DTT, cyanide and arsenite, the amount of label present in each chain length from four wax classes dominated by even chain lengths was first summed. These results which are presented in Table IX together with the knowledge of the effect of these inhibitors on the odd chain lengths (37) form the basis of the conclusions drawn. 


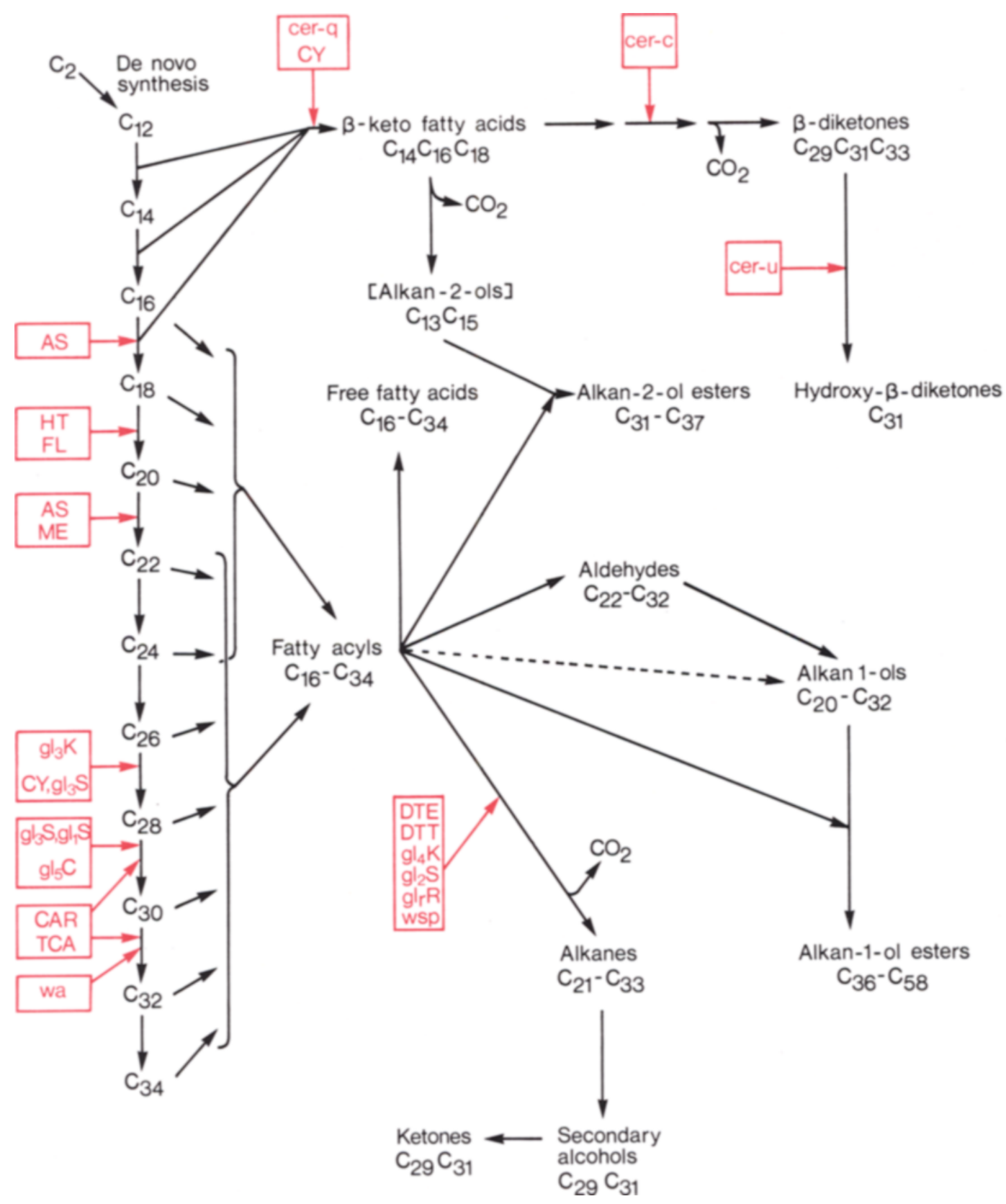

Figure 5. Summary of effects of chemicals, genes and $35^{\circ} \mathrm{C}(\mathrm{HT})$ on the biosynthesis of the epicuticular wax classes. The general biosynthetic relationships among the wax classes, which are based upon the schemes presented in references $31 \mathrm{og} 51$, have been modified to include the present results. The elongation pathway leading to the alkanes etc. has been indicated as a single elongation mechanism in order not to complicate the figure. Whether or not more than one elongation mechanism is involved is not yet known. The most common chain lengths of the wax classes are indicated. Hypothetical intermediates are indicated by the use of brackets. Solid lines indicate primary pathways; dotted line possible alternate biosynthetic pathway. The point(s) of action of the chemicals (DTT, dithiothreitol; DTE, dithioerythritol; ME, mercaptoethanol; CAR, thiocarbamates, specifically: dichloroallyl diisopropylthiocarbamate, S-ethyldipropylthiocarbamate and $\alpha$-chloroallyl diethyldithiocarbamate; TCA, trichloroacetate; AS, arsenite; CY, cyanide; FL, fluoride) and the genes (see Table $\mathrm{X}$ ) are indicated by red arrows. In the text references are given which support the points of action indicated for the chemicals and HT. Those for the genetic blocks are given in Table X. 


\subsection{Identification of new elongation blocks 4.1.1. Mercaptoethanol}

Treatment with $\mathrm{ME}$ resulted in a 2.4 fold increase in the synthesis of $\mathrm{C}_{18}$ and $\mathrm{C}_{20}$ chains, a small increase in the synthesis of $\mathrm{C}_{22}$ and $\mathrm{C}_{24}$ chains, but had no marked effect on the synthesis of the $C_{32}$ chains when compared to the control (Table IX). On the basis of these results, the primary effect of $\mathrm{ME}$ on wax synthesis is to block the elongation of $\mathrm{C}_{20}$ to $\mathrm{C}_{22}$ chain lengths (Fig. 5). BUCKNER and Kolattukudy (5) had earlier deduced from their studies using tissue slices of pea leaves, however, that neither ME nor dithioerythritol (DTE) inhibited the elongation process. The data which they present tends to support their contention with respect to DTE. That is, a marked accumulation of label occurred in the longest chain of interest, specifically in the $C_{32}$ aldehyde. No accumulation of label, however, occurred in the $\mathrm{C}_{32}$ chains of the other lipid classes. Their experimental results with $\mathrm{ME}$ are quite different. Compared to the DTE experiments, relatively little label was found in the $C_{32}$ aldehyde and none was reported in the $C_{32}$ chains of the other lipid classes. A dramatic accumulation of label in the $C_{22}$ to $C_{32}$ chains of the aldehydes and acyl moieties of the short chain esters is the most obvious effect of their $M E$ treatment. Whether elevated amounts of label were present in the $\mathrm{C}_{24}-\mathrm{C}_{28}$ acyl moieties of the polar lipids, as they imply, is highly questionable (see their Fig. 2). When combined with the observation that no label was detected in these two lipid classes for $C_{20}$ and shorter chains, BUCKNER and KOLATTUKUDY's results (5) certainly do not appear to support the hypothesis that $\mathrm{ME}$ causes a block in elongation between $\mathrm{C}_{20}$ and $\mathrm{C}_{22}$.

In seeking an explanation for the inconsistencies between the action of ME on the synthesis of the epicuticular waxes of pea leaves and barley spikes it may be significant that while only one elongation system draws on the pool of wax precursors in peas, two elongating systems do so in barley (Fig. 5). On pea leaves the alkanes and secondary alcohols compose $47-57 \%$ of the wax $(34,25)$, while on barley spikes the alkanes amount to only $16 \%(50)$ and the $\beta$-diketone lipid classes to $50 \%$ (51). Thus since a far greater proportion of the acyl precursors on barley spikes enter the $\beta$-diketone elongating system than that leading to the alkanes, it might be reasonable to expect that the pool of long chain endogenous precursors available for the synthesis of the alkanes is much smaller in barley spikes than in pea leaves. Upon introduction of $\mathrm{ME}$ this pool of acyl chains with $\mathrm{C}_{22}-\mathrm{C}_{28}$ carbons can still undergo further elongation and/or be channeled into other wax classes. The final result is to mask the effect of $\mathrm{ME}$ on the $\mathrm{C}_{20}-\mathrm{C}_{22}$ elongation step. That a pool of endogenous long chain acyl intermediates is available for elongation is suggested by Kolattukudy and Buckner's experiments with a $27,000 \mathrm{x}$ g supernatant from extracts of pea epidermis which was shown to be capable of the addition of single $\mathrm{C}_{2}$-units to endogenous fatty acids having as many as 16-22 carbon atoms (28). The above hypothesis can

\section{Table IX}

The effects of pre-incubations with inhibitors on the incorporation of $\left[2-{ }^{14} \mathrm{C}\right]$-acetate into various chain lengths of the free fatty acids, primary alcohols, aldehydes and acid moieties of the short chain esters.

\begin{tabular}{|c|c|c|c|c|c|c|c|c|c|c|c|}
\hline \multirow{2}{*}{$\begin{array}{l}\text { Experimental } \\
\text { condition }\end{array}$} & \multirow{2}{*}{ ( $\mu$ moles) } & \multirow[b]{2}{*}{16} & \multirow[b]{2}{*}{18} & \multirow[b]{2}{*}{20} & \multicolumn{3}{|c|}{$\begin{array}{l}\text { Chain length } \\
\left(\mathrm{cpm} \times 10^{-3}\right.\end{array}$} & \multirow[b]{2}{*}{28} & \multirow[b]{2}{*}{30} & \multirow[b]{2}{*}{32} & \multirow[b]{2}{*}{ Total } \\
\hline & & & & & 22 & 24 & 26 & & & & \\
\hline Control & & - & 9 & 73 & 41 & 26 & 60 & 45 & 74 & 272 & 600 \\
\hline Dithiothreitol & (36) & 21 & 20 & 99 & 42 & 28 & 52 & 43 & 89 & 457 & 851 \\
\hline Mercaptoethanol & (60) & 36 & 113 & 166 & 61 & 42 & 38 & 29 & 31 & 306 & 822 \\
\hline Cyanide & (6) & - & 183 & 266 & 104 & 131 & 182 & 92 & 98 & 348 & 1404 \\
\hline & $(60)$ & - & 72 & 121 & 59 & 111 & 117 & 40 & 41 & 97 & 658 \\
\hline Arsenite & (6) & - & 112 & 280 & 66 & 52 & 40 & 19 & 22 & 152 & 743 \\
\hline
\end{tabular}


be tested. Firstly, similar experiments can be made using tissue slices of seedling leaves from barley or maize (3). Since the $\beta$-diketone elongation system is not operating in either of these systems, the possibility exists that a larger pool of endogenous long chain precursors will be present that will aid in obscuring the $\mathrm{C}_{20}-\mathrm{C}_{22}$ block caused by ME. Secondly, an analysis of the free fatty acids in the pea system should be made as this was one of the wax classes in the present investigations in which the accumulation of label in the $\mathrm{C}_{20}$ and shorter chains was most marked. Unfortunately, BUCKNER and KOLATTUKUdY (5) did not separate the small amount of free fatty acids present in the wax from the large amount of internal lipids which together composed their polar lipid fraction.

\subsubsection{Arsenite}

The primary effect of arsenite is to block the elongation sequence leading to the $\beta$-diketones (37). Analysis of the distribution of label within the $\beta$-diketone molecule after arsenite treatment indicated that this effect was most likely closely related to the established ability of arsenite to block elongation of $\mathrm{C}_{16}-\mathrm{C}_{18}(9,10,15-$ 17). The marked accumulation of label in chains longer than $\mathrm{C}_{16}$ in the present analysis was unexpected. The overall distribution of label among the even chains after treatment with arsenite is very similar to that after ME treatment, except that only half as much label is present in the $\mathrm{C}_{32}$ chains (Table IX). These results infer that arsenite blocks the $\mathrm{C}_{20}-\mathrm{C}_{22}$ elongation step in an even more effective manner than does ME (Fig. 5).

\subsubsection{Significance of $a C_{20}-C_{22}$ elongation block}

If the overall distribution of label among the $\mathrm{C}_{16}{ }^{-} \mathrm{C}_{24}$ chains after treatment with $\mathrm{ME}$ or arsenite is examined, a resemblance to both the mass and radioactivity distribution of the ester fatty acid moieties is evident (Tables VIII and 1X). For this reason the ester acid data has not been included in Table IX. The ester acids also contained a relatively small amount of label ( $\max 10 \%$ ) compared to the other four wax classes. Furthermore, treatment with ME has little effect on the ${ }^{14} \mathrm{C}$ distribution except that somewhat more counts are found in the $\mathrm{C}_{16}$ and $\mathrm{C}_{18}$ chains (Table VIII). These results imply that the blocking action of $\mathrm{ME}$ and arsenite results in a channeling of acyl moieties into the pathways normally leading to the ester fatty acids. This has been indicated in Fig. 5 by the use of separate brackets to show departure of the $\mathrm{C}_{16}-\mathrm{C}_{24}$ and the $\mathrm{C}_{22}-\mathrm{C}_{32}$ fatty acyl chains from the elongation sequence. Whether or not the action of these inhibitors is (i) to interrupt a single elongation sequence, (ii) to have no effect on the elongation sequence leading to the ester acids but to block that leading to the alkanes and other lipid classes or (iii) to prevent the entrance of the $C_{20}$ acyl chains into a new elongation sequence leading to the alkanes etc. cannot be determined from the presently available data. By examining the distribution of label among the ester fatty acid moieties $(5,29)$ and noting that an accumulation of label occurs in the $C_{22}$ chains of the free and ester bound acids after treatment with thiocarbamates (29), the analogous block in peas appears to occur between $\mathrm{C}_{22}$ and $\mathrm{C}_{24}$. From his results NetTing (38) has suggested that the final elongation leading to the long chain aldehydes in B. oleracea starts from an acyl chain having 22 carbons.

\subsubsection{Cyanide}

Although synthesis of all chain lengths is stimulated at the lower concentration of cyanide, the magnitude of the increase is relatively small for the three longest chains compared to the shorter ones. This sharp boundary between $\mathrm{C}_{26}$ and $\mathrm{C}_{28}$ is even more evident at the higher concentration of cyanide which actually markedly depressed synthesis of $\mathrm{C}_{28}$ $\mathrm{C}_{32}$ while that of the $\mathrm{C}_{26}$ and shorter chains remained elevated (Table IX). These results suggest that at higher concentrations cyanide may inhibit the $\mathrm{C}_{26}-\mathrm{C}_{28}$ elongation step (Fig. 5). How this happens is unknown. The same possibilities mentioned above for the $c_{20}-C_{22}$ block are also applicable in this case. At the lower concentration of cyanide this inhibition of $\mathrm{C}_{26}-\mathrm{C}_{28}$ either does not occur or the effect is masked by the marked stimulation that cyanide has on the synthesis of all wax classes except the $\beta$-diktones (37). The magnitude of the in- 
crease is far in excess of what might be expected if only a re-channeling of the acyl precursors that normally enter the $\beta$-diketone elongation system were occurring. The major effect of cyanids is an inhibition of $\beta$-diketone synthesis (37). This is also depicted in Fig. 5. The position of the block is shown before the $\beta$ keto fatty acids $(37,51)$. Whether the block also influences those $\beta$-keto fatty acids leading to the alkan-2-ols remains to be confirmed.

\subsection{Stimulation of wax biosynthesis by low con- centrations of inhibitors}

With the lowest two concentrations of cyanide employed, a very substantial increase of label occurred in all wax classes except the $\beta$ diketones (37). A ccumulation of label in the latter was only slightly elevated by $0.6 \mu$ moles and was somewhat depressed by $6 \mu$ moles (37). The following sequence of events may be responsible for this stimulation. The production of NADPH by non-cyclic electron flow in the chloroplasts is not sensitive to cyanide at low concentrations (4). The electron transport chain which links the reduced nicotinamide nucleotides to oxygen, however, is sensitive to low cyanide concentrations (45). Thus a high level of NADPH is produced which can be consumed in lipid biosynthesis. NADPH is required not only in the de novo synthesis of fatty acids (11), but also in the formation of very long chain fatty acids (28) and in the synthesis of primary alcohols (27). In addition, NADH is probably required in the synthesis of aldehydes (27). A large stimulation of the overall fatty acid synthesis would, in turn, provide a substantial increase in the acyl precursors available for the wax elongation systems. The results obtained by OUITRAKUl et al. (41) and COHEN et al. (6) indicated that the non-cyclic electron flow is sensitive to high cyanide concentrations. This would lower the amount of available NADPH and consequently wax biosynthesis would be inhibited at $360 \mu$ moles. This hypothesis assumes that the physiological concentrations of cyanide within the cells of the intact barley spike system are in the same range as those giving the effects noted above.

A marked stimulation of the synthesis of all the wax lipids occurred with low concentrations of ME (Table I). A similar effect was reported for imidazol when 1-50 $\mu$ moles were used per leaf (20). Preliminary experiments with intact barley spikes indicated an analogous stimulation (170\%) when $60 \mu$ moles imidazole per ten spikes were imployed. The mechanisms by which ME and imidazole enhance the biosynthesis of the epicuticular wax classes will not be speculated upon at present.

\subsection{Biosynthetic relationship of the short chain esters to the other lipid classes}

The short chain esters have not been reported before in barley waxes and, even in the present study, were only detected because of their very high specific activity. Their synthesis was stimulated by $\mathrm{ME}$, arsenite and cyanide but repressed by DTT. A short chain ester has also been reported in pea waxes but it was found only after ME treatment (5). Whether or not the same alcohol moiety is involved in both the barley spikes and pea leaves is unknown. Since the distribution of chain lengths among the acid moieties of the short chain esters is quite different from that of the ester acids in barley, the two esterification systems involved differ in more than their choice of alcohol moiety. The short chain esters are not included in Fig. 5 as they do not form a significant part of the wax in terms of mass. The labeling pattern of their acid and their alcohol moieties in the control and after the various inhibitor treatments suggests however, that they originate from the elongation sequence leading to the alkanes.

\subsection{Previously identified blocks in the elongation system(s) leading to even chain wax classes}

\subsubsection{Inhibitors}

TCA was the first of the chemicals investigated and subsequently shown to inhibit elongation in a number of plant systems; $B$. oleracea $(19,21,36)$, Nicotiana tabacum (22), P. sativum (5) and Vicia faba (30). A single elongation block has not been identified, instead the severity of the inhibition increased as the chain length increased. Therefore in Fig. 5 a blocking action by TCA is indicated between $\mathrm{C}_{28}$ and $\mathrm{C}_{30}$ and also between $\mathrm{C}_{30}$ and $\mathrm{C}_{32}$.

Three thiocarbamates were found to inhibit 
the synthesis of $C_{31}$ hydrocarbons in $P$. sativum leaves at a concentration that did not affect the synthesis of $C_{26}$ and $C_{28}$ primary alcohols (29). This was interpreted as evidence that thiocarbamates inhibit the elongation mechanism at the $\mathrm{C}_{28}$ and/or $\mathrm{C}_{30}$ steps as indicated in Fig. 5. At higher concentrations synthesis of the $C_{26}$ and $\mathrm{C}_{28}$ primary alcohols was also inhibited and label accumulated in the $\mathrm{C}_{22}$ fatty acids. This result indicates that a second block brought about by thiocarbamates exists between $\mathrm{C}_{22}$ and $\mathrm{C}_{24}$.

Fluoride ions and a temperature of $35^{\circ} \mathrm{C}$ were found to inhibit the formation of $\mathrm{C}_{20}$ from $C_{18}$ in germinating peas and safflower seeds (9). Since the effects on these two agents on the epicuticular wax lipids were not investigated, a tentative block between $\mathrm{C}_{18}$ and $\mathrm{C}_{20}$ is indicated in Fig. 5.

\subsubsection{Genetic blocks}

A comparison between the composition of the wax present on wild type and on wa leaves of $P$. sativum $(13,34)$ demonstrated that this gene is involved in the elongation of $\mathrm{C}_{30}-\mathrm{C}_{32}$ in the sequence leading to the alkanes (Fig. 5). The first study of the $w b$ gene in P. sativum intimated a role for $w b$ in the elongation from $\mathrm{C}_{26}$ -
$\mathrm{C}_{28}$ (34). Recent results do not support this (13), and therefore no site of action for $w b$ is indicated in Fig. 5. A similar analysis of B. oleracea waxes $(2,35)$ led to the conclusion that (i) the action of $g l_{3} S$ is to inhibit elongation from $\mathrm{C}_{26}-\mathrm{C}_{28}$ and more strongly that from $\mathrm{C}_{28}$ $\mathrm{C}_{30}$, while (ii) $\mathrm{gl} l_{1} S$ acts only on the elongation of $\mathrm{C}_{28}-\mathrm{C}_{30}$ (Fig. 5, Table X). In addition to compositional analyses, the roles of the $g l_{3} \mathrm{~K}$ and $\mathrm{gl} \mathrm{C}_{\mathrm{C}}$ (also from B. oleracea, see Table X) were investigated with the aid of radioactive precursors $(36,38)$. The identified elongation blocks occurring between $\mathrm{C}_{26}$ and $\mathrm{C}_{30}$ are also included in Fig. 5.

\subsection{Decarboxylation blocks}

\subsubsection{Inhibitors}

The results of the present analysis with DTT (see also 37) substantiate BUCKNER and KolATTUKUDY's (5) identification of DTT as a decarboxylation inhibitor. Their detailed analysis was actually carried out using DTE. It is possible to roughly estimate, from the data they present, the increase of label in the $\mathrm{C}_{32}$ chains of the wax and the concurrent decrease in the $C_{31}$ chains. The ratio of increase in $C_{32}$ to decrease in $C_{31}$ was only 0.23 , indicating that not all of the label prevented from entering the

\section{Table X}

Identification of gene symbols used in Fig. $5^{\mathrm{a}}$

\begin{tabular}{llll}
\hline Plant species & Varietyb & Geneb & Referencesc \\
\hline Brassica oleracea & Marrow stem Kale & $g l_{3} \mathrm{~K}$ & $(35,38)$ \\
Brassica oleracea & Marrow stem Kale & $g l_{4} \mathrm{~K}$ & $(35,36,38)$ \\
Brassica oleracea & Cauliflower & $g l_{3} \mathrm{C}$ & $(35,36)$ \\
Brassica oleracea & Brussel Sprout & $g l_{1} \mathrm{~S}$ & $(2)$ \\
Brassica oleracea & Brussel Sprout & $g l_{2} \mathrm{~S}$ & $(2)$ \\
Brassica oleracea & Brussel Sprout & $g l_{3} \mathrm{~S}$ & $(2)$ \\
Brassica napus & Rape (Rigo) & $g l_{r} \mathrm{R}$ & $(12)$ \\
Pisum sativum & & $w a$ & $(13,34)$ \\
Pisum sativum & & $w s p$ & $(13,34$ \\
Hordeum vulgare & Bonus & $c e r-q$ & $(47,51)$ \\
Hordeum vulgare & Bonus & $c e r-c$ & $(47,51)$ \\
Hordeum vulgare & Bonus & $c e r-u$ & $(47,51)$ \\
\hline
\end{tabular}

a Only those genes whose site of action on the wax biosynthetic apparatus have been clearly pinpointed are included.

b Since the same symbol (e.g. $g l_{1}$ ) has been used for mutants induced in more than one variety of Brassica, a letter indicating the variety has been attached to the gene symbols to avoid confusion.

c Reference number (s) is (are) to the paper(s) leading to the conclusion as to the site(s) of action shown in Fig. 5. 
$C_{31}$ chains by DTE accumulated in the $C_{32}$ chains. In the present study with DTT (see also 37 ), the same ratio equals 0.69 , a value somewhat closer to 1 , which is the expected in an ideal situation. The higher ratio in barley is in part due to the fact that data for more of the wax classes is available than it is for the pea system (5). If a similar calculation is made for the ME experiments the following ratios are obtained: barley 0.12 and pea 0.06 . That the ratio for ME is 5.8 times less than for DTT in barley and 3.8 times less than for DTE in peas is strong evidence that the primary effect of $\mathrm{ME}$ is not on decarboxylation. Instead as discussed in section 4.1.1., the primary effect of ME on wax biosynthesis is on elongation and the decarboxylation effect is of relatively minor importance (Fig. 5).

\subsubsection{Genetic blocks}

Compositional analyses of the waxes from P. sativum and its mutant wsp as well as of those from the wild type Brassicas and the mutants $g l_{4} \mathrm{~K}, g l_{2} \mathrm{~S}$ and $g l_{r} R$ (Table $\mathrm{X}$ ) led to the conclusion (shown in Fig. 5) that the primary effect of these genes was on the decarboxylation reaction(s) of the elongated fatty acyl precursors of the alkanes. In addition to compositional analyses, the role of the $g l_{4} \mathrm{~K}$ gene was investigated using radioactive precursors with a similar result (see Fig. 5).

\subsection{Biosynthesis of the primary alcohols}

Two alternative routes to the primary alcohols are shown in Fig. 5. Tracer studies with barley leaves indicated that the $C_{26}$ aldehyde was an intermediate in the synthesis of the $\mathrm{C}_{26}$ alcohol (8). The mechanism involved is probably similar to that shown to occur in Mycobacterium tuberculosis (44), Clostridium butyricum (7) or B. oleracea (27) where the aldehydes are true intermediates of the alcohols. In the present study the stimulation of $\mathrm{C}_{32}$ aldehyde synthesis after treatment with the decarboxylation inhibitor DTT was accompanied by a large accumulation of label in the $\mathrm{C}_{32}$ primary alcohols. Treatment with the elongation inhibitors $\mathrm{ME}$, arsenite and the higher concentration of cyanide did not, however, affect the amount of label present in the $\mathrm{C}_{32}$ aldehyde and alcohol in any parallel manner. In addition to the formation of primary alcohols via an aldehyde, as mentioned above, they have also been shown to come directly from a fatty acyl-CoA intermediate in Euglena gracilis $(18,24)$. This pathway is indicated by the dotted line in Fig. 5. In some B. oleracea waxes branched ester fatty acids as well as free and esterified alcohols have been identified. No branched components were present in the aldehydes, however, $(12,39)$ indicating that in B. oleracea at least two pathways lead to the primary alcohols. The situation in barley remains to be investigated.

\subsection{Biosynthesis of $\beta$-diketones and esterified alkan-2-ols}

While this paper has dealt with the effect of chemical inhibitors on the synthesis of the even chained wax lipids of barley spikes, the predominant wax classes are the $\beta$-diketones with 31 carbon atoms. As shown in Fig. 5 the elongation sequence leading to the $\beta$-diketones is a different one from that leading to the alkanes $(37,51)$. From a study of the effects of inhibitors on $\beta$-diketone synthesis (see sections 4.1.2. and 4.1.4.), a $C_{18} \beta$-keto acid has been suggested as the starting point for the elongation to the final carbon, chain of the $\beta$ diketones $(37,51)$. This keto acid as well as the $C_{16}$ and $C_{14}$ keto acids which arise from $C_{16}, C_{14}$ and $C_{12}$ acids by the addition of one $C_{2}$-unit, respectively, are also thought to serve as precursors for the esterified alkan-2-ols (see 37). The latter wax class was found to be more closely related biosynthetically to the $\beta$ diketones than to any of the other wax classes. This deduction was based on a compositional analysis of the waxes of a number of eceriferum (cer) mutants (51). The blocks caused by three of these mutants, cer- $q,-c$ and $-u$ are shown in Fig. 5 (51). These three genes do not affect the chain length distributions of any of the wax classes arising via the elongation sequence leading to the alkanes ( $P$. von WetTSTEINKNOWLES, pers. commun.). 


\section{ACKNOWLEDGEMENT}

I wish to express my sincere gratitude to Dr. PENNY Von WETTSTEIN-KNOWLES, who strongly influenced this work through inspiring collaboration, innumerable discussions and for her assistance in preparing this communication. Thanks are also due to Dr. C. G. KanNANGARA for stimulating discussions. I am indebted to Nina Rasmussen and ANN-Sofi STEINHOLtZ for making the figures, and to the personnel of the Phytotron at the Royal College of Forestry, Stockholm for growing the plants. This work was supported in part by grant GM 22051 of the National Institutes of Health, U. S. Public Health Service.

\section{REFERENCES}

1. Allebone, J. E., R, J. Hamilton, B. A. Knights, B. S. Middleditch \& D. M. Power: Cuticular leaf waxes. Part II. Chenopodium album L. and Lolium perenne L. Chem. Phys. Lipids 4, 37-46 (1970)

2. BAKER, E. A.: The influence of environment on leaf wax development in Brassica oleracea var. gemmifera. New. Phytol. 73, 955-966 (1974)

3. Bianchi, G. \& F. Salamini: Glossy mutants of maize. IV. Chemical composition of normal epicuticular waxes. Maydica 20, 1-3 (1975)

4. Bishop, N. I. \& J. D. SpIKES: Inhibition by cyanide of the photochemical activity of isolated chloroplasts. Nature 176, 307-308 (1955)

5. Buckner, J.S. \& P. E. Kolattukudy: Specific inhibition of alkane synthesis with accumulation of very long chain compounds by dithioerythritol, dithiothreitol and mercaptoethanol in Pisum sativum. Arch. Biochem. Biophys. 156, 35-45 (1973)

6. Cohen, W. S. \& R. E. MCCARTY: Reversibility of the cyanide inhibition of electron transport in spinach chloroplast thylakoids. Biochem. Biophys. Res. Commun. 73, 679-685 (1976)

7. Day, J. I. E., H. Goldfine \& P. O. Hagen: Enzymic reduction of long-chain acyl-CoA to fatty aldehyde and alcohol by extracts of Clostridium butyricum. Biochem. Biophys. Acta 218, 179-182 (1970)

8. GIESE, B. N.: Effects of light and temperature on the composition of epicuticular wax of barley leaves. Phytochem. 14, 921-929(1975)
9. Harwood, J. L. \& P. K. StumpF: Fat metabolism in higher plants. XLIII. Control of fatty acid synthesis in germinating seeds. Arch. Biochem. Biophys.: 142, 281-291 (1971)

10. HÁwood, J. L. \& P. K. STUMPF: Fat metabolism in higher plants. LI. Palmitic and stearic synthesis by avocado supernatant system. Arch. Biochem. Biophys. 148, 282-290 (1972)

11. HARwood, J. L.: Fatty acid biosynthesis. In: Recent Advances in the Chemistry and Biochemistry of Plant Lipids. T. Galliard \& E. I. Mercer eds. Academic Press pp. 95-112 (1975)

12. Holloway, P. J., G. A. Brown, E. A. Baker \& M. J. K. MACEY: Chemical composition and ultrastructure of the epicuticular wax in three lines of Brassica napus (L). Chem. Phys. Lipids 19, 114-127 (1977)

13. Holloway, P. J., G. M. Hunt, E. A. Baker \& M. J. K. MACEY: Chemical composition and ultrastructure of the epicuticular wax in four mutants of Pisum sativum (L). Chem. Phys. Lipids (In press)

14. Jaworski, J. G. \& P. K. SrumpF: Fat metabolism in higher plants. Properties of a soluble stearylacyl carrier protein desaturase from maturing Carthamus tinctorius. Arch. Biochem. Biophys. $162,158-165$ (1974)

15. JAworski, J. G., E. E. Goldschmidt \& P. K. STUMPF: Fat metabolism in higher plants. Properties of the palmityl acyl carrier protein: Stearyl acyl carrier protein elongation system in maturing safflower seed extracts. Arch. Biochem. Biophys. 163, 769-776 (1974)

16. Kannangara, C. G. \& P. K. Stumpf: Fat metabolism in higher plants. L. The biosynthesis of polyunsaturated fatty acids by isolated spinach chloroplasts. Arch. Biochem. Biophys. 148, 414-424 (1972)

17. Kannangara, C. G. \& P. K. StumpF: Fat metabolism in higher plants. XLVII. The effect of nitrite and other anions on the formation of unsaturated fatty acids by isolated chloroplasts. Plant Physiol. 49, 497-501 (1972)

18. Khan, A. A. \& P. E. Kolattukudy: A microsomal fatty acid synthetase coupled to acylCoA reductase in Euglena gracilis. Arch. Biochem. Biophys. 158, 411-420 (1973)

19. Kolattukudy, P. E.: Biosynthesis of wax in Brassica oleracea. Biochem. 4, 1844-1855 (1965)

20. Kolattukudy, P. E.: Biosynthesis of wax in Brassica oleracea. Relation of fatty acids to wax. Biochem. 5, 2265-2275 (1966)

21. Kolattukudy, P. E.: Biosynthesis of paraffins in Brassica oleracea: Fatty acid elongation- 
decarboxylation as a plausible pathway. Phytochem. 6, 963-975 (1967)

22. Kolattukudy, P. E.: Further evidence for an elongation-decarboxylation mechanism in the biosynthesis of paraffins in leaves. Plant Physiol. 43, 375-383 (1968)

23. Kolattukudy, P. E.: Biosynthesis of long-chain hydrocarbons and waxy esters is discussed. Science 159, 498-505 (1968)

24. Kolattukudy, P. E.: Reduction of fatty acids to alcohols by cell-free preparations of Euglena gracilis. Biochem. 9, 1095-1102 (1970)

25. Kolattukudy, P. E.: Composition of the surface lipids of pea leaves (Pisum sativum). Lipids 5 , 398-402 (1970)

26. Kolattukudy, P. E.: Biosynthesis of cuticular lipids. Annu. Rev. Plant Physiol. 21, 163-192 (1970)

27. Kolattukudy; P. E.: Enzymatic synthesis of fatty alcohols in Brassica oleracea. Arch. Biochem. Biophys. 142, 701-709 (1971)

28. Kolattukudy, P. E. \& J. S. Buckner: Chain elongation of fatty acids by cell-free extracts of epidermis from pea leaves (Pisum sativum). Biochem. Biophys. Res. Commun. 46, 801-807 (1972)

29. Kolattukudy, P. E. \& L. Brown: Inhibition of cuticular lipid biosynthesis in Pisum sativum by thiocarbamates. Plant. Physiol. 53, 903-906 (1974)

30. Kolattukudy, P. E., R. Croteau \& L. Brown: Structure and biosynthesis of cuticular lipids. Hydroxylation of palmitic acid and decarboxylation of $C_{28}, C_{30}$ and $C_{32}$ acids in Vicia faba flowers. Plant Physiol. 54, 670-677 (1974)

31. Kolattukudy, P. E., R. Croteau \& J. S. BUCKNER: Biochemistry of plant waxes. In: Chemistry and Biochemistry of Natural Waxes. P. E. Kolattukudy ed. Elsevier, Amsterdam pp. 289-347(1976)

32. Kranz, Z. H., J. A. Lamberton, K. E. Murray \& A. H. Redcliffe: Sugar cane wax. II. An examination of the constituents of sugar-cane cuticle wax by gas chromatography. Aust. J. Chem. 13. 498-505 (1960)

33. Lundqvist, U., P. von WettStein-Knowles \& D. VON WETTSTEIN: Induction of eceriferum mutants in barley by ionizing radiations and chemical mutagens II. Hereditas (Lund) 59, 473-504 (1968)

34. MACEY, M. J. K. \& H. N. Barber: Chemical genetics of wax formation on leaves of Pisum sativum. Phytochem. 9, 5-12 (1970)

35. MaceY, M. J. K. \& H. N. Barber: Chemical genetics of wax formation on leaves of Brassica oleracea. Phytochem. 9, 13-23 (1970)
36. MaceY, M. J. K.: Wax synthesis in Brassica oleracea as modified by trichloroacetic acid and glossy mutations. Phytochem. 13, 1353-1358 (1974)

37. Mikkelsen, J. D. \& P. von Wettstein-Knowles: Biosynthesis of $\beta$-diketones and hydrocarbons in barley epicuticular wax. Arch. Biochem. Biophys. (in press)

38. Netting, A. G.: Chemical genetics of waxes in plants. Ph. D. thesis (University of New South Wales, Sydney, Australia) (1971)

39. Netting, A. G., M. J. K. Macey \& H. N. BARBER: 'Chemical genetics of a sub-glaucous mutant of Brassica oleracea. Phytochem. 11, 579-585 (1972)

40. Netting, A. G. \& C. Barr: Design of an accurate and versatile radio-gas liquid chromatograph. Anal. Chem. (in press) (1977)

41. Ouitrakul, R. \& S. Izawa: Electron transport and photophosphorylation in chloroplasts as a function of the electron acceptor. II. Acceptorspecific inhibition by KCN. Biochem. Biophys. Acta 305, 105-118 (1973)

42. Schmid, H. H. O. \& P. C. Band: Naturally occuring long-chain $\beta$-hydroxyketones. J. Lipid Res. 12, 198-202 (1971)

43. StumpF, P. K. \& N. K. Boardman: Fat metabolism in higher plants. XXXIX. Effect of adenosine triphosphate and triton $X-100$ on lipid synthesis by isolated chloroplasts. J. Biol. Chem. 245, 2579-2587 (1970)

44. Wang, L., K. Takayama, D. S. Goldman \& H. K. Schoes: Synthesis of alcohol and wax ester by a cell-free system in Mycobacterium tuberculosis. Biochem. Biophys. Acta 260, 41-48 (1972)

45. WEBB, J. L.: Effects of various factors on inhibition. In: Enzyme and Metabolic Inhibitors. J. L. Webb ed. Academic Press Vol. 1, 747-857 (1963)

46. Wettstein-Knowles, P. von: The molecular phenotypes of the eceriferum mutants. In: Proc. 2nd. Int. Barley Genet. Symp. (1969) R. A. Nilan ed., Pullmann, Wash., USA, Washington State Univ. Press, pp. 146-193 (1971)

47. Wettsteln-KNowles, P. vON: Genetic control of $\beta$-diketone and hydroxy- $\beta$-diketone synthesis in epicuticular waxes of barley. Planta 106, 103-130 (1972)

48. Wettstein-KNowles, P. von: Gene mutations in barley inhibiting the production and use of $\mathrm{C}_{26}$ chains in epicuticular wax formations. Febs Letters 42, 187-191 (1974)

49. Wettstein-Knowles, P. von \& A. G. Netting: Composition of epicuticular waxes on barley 
spikes. Carlsberg Res. Commun. 41, 225-235 (1976)

50. Wettstein-KNowles, P. vON \& A. G. Netting: Esterified alkan-1-ols and alkan-2-ols in barley epicuticular wax. Lipids 11, 478-484 (1976)

51. WetTSTEIN-KNOWLes, P. voN: Biosynthetic relationships between $\beta$-diketones and esterified alkan-2-ols deduced from epicuticular wax of barley mutants. Molec. gen. Genet. 144, 43-48 (1976) 